\title{
North American transect of stable hydrogen and oxygen isotopes in water beetles from a museum collection
}

\author{
Maarten van Hardenbroek • Darren R. Gröcke • \\ Peter E. Sauer $\cdot$ Scott A. Elias
}

Received: 1 August 2011/Accepted: 26 May 2012/Published online: 17 June 2012

(C) Springer Science+Business Media B.V. 2012

\begin{abstract}
Museum collections contain a wealth of insect remains originating from a wide geographic range, which can be used to investigate their utility as a proxy for environmental isotope ratios. Chitinous remains of insects such as beetles (Coleoptera) are chemically stable and their stable isotope composition is strongly related to that of environmental water in the period of cuticle formation. We present a dataset of chitin $\delta \mathrm{D}$ and $\delta^{18} \mathrm{O}$ in two genera of water beetles from a museum collection containing 40 locations for
\end{abstract}

Electronic supplementary material The online version of this article (doi:10.1007/s10933-012-9623-4) contains supplementary material, which is available to authorized users.

M. van Hardenbroek ( $\square)$

Institute of Plant Sciences and Oeschger Centre for Climate Change Research, University of Bern, Altenbergrain 21, 3013 Bern, Switzerland

e-mail: maarten.vanhardenbroek@ips.unibe.ch

D. R. Gröcke

Science Laboratories, Department of Earth Sciences, Durham University, South Road, Durham DH1 3LE, UK e-mail: d.r.grocke@durham.ac.uk

P. E. Sauer

Department of Geological Sciences, Indiana University, Bloomington, IN 47405, USA

e-mail: pesauer@indiana.edu

\section{S. A. Elias}

Department of Geography, Royal Holloway University of London, Egham Hill, Egham TW20 0EX, UK e-mail: s.elias@rhul.ac.uk
Helophorus (water scavenging beetles) and 48 locations for Hydroporus (predaceous diving beetles) that were selected from latitudes $27-82^{\circ} \mathrm{N}$ in North America. Only two genera were used to minimize inter-sample variation caused by species-specific differences in metabolic effects, feeding strategy, habitat, and life cycle. The isotopic composition of water beetle exoskeletons had a strong latitudinal trend (NorthSouth) from -160 to $+65 \%$ for $\delta \mathrm{D}$ and from 7 to $34 \%$ or $\delta^{18} \mathrm{O}$, paralleling gradients of isotopes in precipitation. Strong relationships were observed between isotopic composition of beetles and modelled July precipitation $\left(0.71<R^{2}<0.82, p<0.001\right)$. The relationship between $\delta \mathrm{D}$ and $\delta^{18} \mathrm{O}$ in the beetle samples had a systematic offset from the global meteoric water line, which was likely caused by metabolic effects during chitin formation. The offset between $\delta \mathrm{D}$ values in beetles and in modelled precipitation was $33 \%$ larger, on average, for Hydroporus compared with Helophorus, suggesting fractionation of hydrogen isotopes during passage through the food chain. This trophic level effect was not observed for stable oxygen isotopes. Furthermore, the observed deviations between isotopic composition of water beetles and modelled precipitation at collection sites were not constant and indicated local hydrological deviations from modelled precipitation. The largest deviations were observed for sites in the Southern US and the Arctic that are highly evaporative and at sites in the Rocky Mountains and Coastal Mountains that were fed by snow melt. Our results indicated that the isotopic 
composition of water beetles from a museum collection was systematically related to $\delta \mathrm{D}$ and $\delta^{18} \mathrm{O}$ values of precipitation at the collection site.

Keywords Water beetles - Stable isotopes - Chitin · Hydrology

\section{Introduction}

The composition of stable oxygen isotopes $\left(\delta^{18} \mathrm{O}\right)$ and stable hydrogen isotopes $(\delta \mathrm{D})$ of environmental water varies widely and systematically across the globe (Bowen et al. 2005; Dansgaard 1964). A strong relationship has been observed between stable isotopes in environmental water and temperature (Dansgaard 1964), which has led to the wide application of $\delta^{18} \mathrm{O}$ and $\delta \mathrm{D}$ in palaeoclimatology, including the stable isotope analysis of various compounds that preserve well in lake sediments. Compounds that are chemically inert after synthesis have been used to infer past $\delta^{18} \mathrm{O}$ of lake water, including authigenic and biogenic carbonates (Eicher and Siegenthaler 1976; Von Grafenstein et al. 1999a), biogenic silica (Barker et al. 2001), aquatic cellulose (Wolfe et al. 2007), and chitin (Wooller et al. 2004). $\delta^{18} \mathrm{O}$ of carbonates is, however, not only affected by lake water $\delta^{18} \mathrm{O}$, but also directly by a temperature-dependent fractionation, and $\delta^{18} \mathrm{O}$ of biogenic silica and aquatic cellulose can be contaminated by terrestrial material (Leng and Barker 2006; Sauer et al. 2001). In contrast, $\delta^{18} \mathrm{O}$ and $\delta \mathrm{D}$ of chitinous remains of lacustrine invertebrates do not appear to be affected by temperature or terrestrial contamination. Wooller et al. (2004) were among the first to demonstrate that $\delta^{18} \mathrm{O}$ of lacustrine invertebrates is related to $\delta^{18} \mathrm{O}$ of regional precipitation, using chironomid remains in surface sediments from four lakes in North America. In a more extensive study of 31 lakes along a North-South transect in Europe, Verbruggen et al. (2011) found a strong relationship between $\delta^{18} \mathrm{O}$ of modelled local precipitation and $\delta^{18} \mathrm{O}$ of remains of both chironomids and Cladocera. A stronger relationship was observed in the same study between $\delta^{18} \mathrm{O}$ of lake water and $\delta^{18} \mathrm{O}$ of invertebrate remains, indicating that the isotope composition of lake water strongly influences $\delta^{18} \mathrm{O}$ of chitinous invertebrate remains. Using culturing experiments with chironomid larvae, Wang et al. (2009) showed that approximately $69 \%$ of the oxygen and approximately $31 \%$ of hydrogen in the larval biomass was derived from environmental water.
Similarly, Nielson and Bowen (2010) showed that approximately $69 \%$ of oxygen and $38 \%$ of hydrogen in lacustrine brine shrimps was derived from environmental water and approximately $10 \%$ of oxygen and $26 \%$ of hydrogen from their diet. Furthermore, Solomon et al. (2009) indicated that 6-39\% of hydrogen in various freshwater invertebrates is derived from environmental water. Together, these experiment-based studies suggest that invertebrate $\delta^{18} \mathrm{O}$ is largely determined by $\delta^{18} \mathrm{O}$ of environmental water, whereas it is expected that invertebrate $\delta \mathrm{D}$ is affected to a large extent by sources other than environmental water. $\delta \mathrm{D}$ of food is one of these sources, and the results of Nielson and Bowen (2010) suggest that $\delta \mathrm{D}$ of food is more important than $\delta \mathrm{D}$ of environmental water in determining $\delta \mathrm{D}$ of lacustrine brine shrimps.

Beetles (Coleoptera) have highly sclerotized chitinous elytra (wing covers) that are very robust and often preserve well in sediment records (Elias 2006), allowing the analysis of stable oxygen and hydrogen isotope composition of their remains (Schimmelmann et al. 1993). A number of studies have compared stable isotope values of local precipitation or environmental water with $\delta^{18} \mathrm{O}$ or $\delta \mathrm{D}$ in beetles and discussed the potential for palaeoclimatic applications (Gröcke et al. 2006; Miller et al. 1988; Schimmelmann et al. 1993). Several of these studies analysed beetles that were taxonomically heterogeneous and did not constrain habitat and feeding type of the beetles.

In this study, we used museum specimens of aquatic beetles, which allowed us to select only a few species of beetles from two genera, minimizing the inter-sample variation caused by species-specific differences in metabolic effects, feeding strategy, habitat and life cycle. The use of museum specimens also allowed us to select specimens originating from a large geographical and climatic range, with minimal travel expenses. An important drawback of museum specimens is that they were collected over nearly a century for investigations focussed on taxonomic and biodiversity rather than stable isotope study. Accordingly, no information is available about the stable isotope composition of the environmental water or the local precipitation of the collection sites. Although this limits the application of museum specimens to infer climatic information, it can be partly overcome by comparing isotopes in beetles with modelled isotopic values of local precipitation (Bowen et al. 2005; Gröcke et al. 2006; Verbruggen et al. 2011). 
We selected beetle specimens that originated from locations along a latitudinal gradient in North America, to test if the strong and systematic spatial patterns of stable oxygen and hydrogen isotopes in local precipitation observed by Dansgaard (1964) could also be observed in beetles from a museum collection and to investigate if these patterns are similar for $\delta^{18} \mathrm{O}$ and $\delta \mathrm{D}$.

\section{Materials and methods}

Water beetle samples

Forty specimens belonging to nine different species in the genus Helophorus and 48 specimens belonging to seven different species in the genus Hydroporus were taken from the Canadian National Collection of Insects (Agriculture and Agri-Food, Ottawa, Canada). The beetle specimens were originally collected between 1913 and 1994. The specimens were selected from locations on a latitudinal transect from 27 to $82^{\circ} \mathrm{N}$ in North America in order to follow expected shifts in isotope values with latitude. Detailed information about the specimens, collection location and isotopic composition can be found in the Electronic Supplementary Material Table 1.

Sample pre-treatment and analysis

First, all samples and an internal chitin standard (Sigma) were rinsed with a solution of $2: 1$ chloroform:methanol to remove waxes, and boiled for $24 \mathrm{~h}$ in a $1 \mathrm{M} \mathrm{NaOH}$ solution to remove proteinaceous material rich in exchangeable hydrogen groups. An important concern with regard to the analysis of hydrogen isotopes of chitinous cuticles is the potential for exchange with hydrogen from the surrounding environment (Schimmelmann and Miller 2002). In this study we reduced the effect of exchangeable hydrogen on inter-sample variability by air equilibrating all samples and an internal chitin standard with the same hydrogen pool in laboratory air moisture (Wassenaar and Hobson 2003). All samples were allowed to equilibrate for at least $96 \mathrm{~h}$ with atmospheric water vapour in the laboratory air (McMaster University, Hamilton, ON, Canada). Hydrogen of the laboratory air moisture was monitored daily throughout the period of sample analysis (20-29 June 2006) by measuring a chitin reference material that followed the same processing as the samples. No changes in $\delta \mathrm{D}$ values were observed in the reference material during the period of analysis. Assuming that all samples received the same proportion of exchangeable hydrogen from lab moisture, no correction of $\delta \mathrm{D}$ values was applied. This technique resulted in an internally consistent data set which was indicated by the strong correlation between $\delta \mathrm{D}$ and $\delta^{18} \mathrm{O}$ in beetle samples (Fig. 1) and allowed us to simultaneously measure hydrogen and oxygen isotopes on a large number of samples with small weight (50-100 $\mu \mathrm{g})$.

Next, the material was weighed using a microbalance, transferred into $6 \times 4 \mathrm{~mm}$ isotope-grade silver capsules, and crushed into small balls. Analyses were performed using a TC/EA connected to a ThermoFinnigan Delta Plus XP isotope-ratio mass-spectrometer. All analyses were run without diluting the samples with helium gas in order to measure hydrogen and oxygen isotopes simultaneously. The results were internally calibrated against the chitin standard and $\mathrm{C}_{36} n$-alkane, an isotopic reference material from Indiana University. ANU sucrose was used as an international isotopic reference material. Repeated measurement of the standards gave standard deviations ( $1 \mathrm{SD})$ of $<0.4 \%$ o $\left(\delta^{18} \mathrm{O}\right)$ and $<5 \%$ o $(\delta \mathrm{D})$. When possible, replicate measurements of beetle samples were analyzed, yielding $1 \mathrm{SD}$ uncertainty estimates of 0.47 and $3.1 \%$ for $\delta^{18} \mathrm{O}$ and $\delta \mathrm{D}$, respectively. All values are reported in the delta notation against Vienna Standard Mean Ocean Water (\%o VSMOW).

\section{Climatic and modelled isotope data}

Isotopic data for environmental water at the time of beetle collection were not available. Therefore, an approximation of isotope values in July precipitation at each sample site was modelled with the online isotope precipitation calculator (www.waterisotopes. org; Bowen and Revenaugh 2003; Bowen et al. 2005; Bowen and Wilkinson 2002). This tool uses the GNIP database (IAEA/WMO 2006) and interpolation algorithms to predict monthly isotope composition of precipitation for any latitude/longitude/altitude combination. In addition, we retrieved mean annual and mean monthly temperatures and precipitation amounts from the nearest weather stations, using 1971-2000 average values from the Canadian Weather Office (www.climate.weatheroffice.ec.gc.ca) and NOAA 
Fig. 1 Linear regression of $\delta \mathrm{D}$ and $\delta^{18} \mathrm{O}$ for Helophorus (solid circles) and Hydroporus (open circles). The global meteoric water line (GMWL) and modelled isotopic composition of July precipitation for the collection sites are included for comparison. One Helophorus outlier is shown in grey

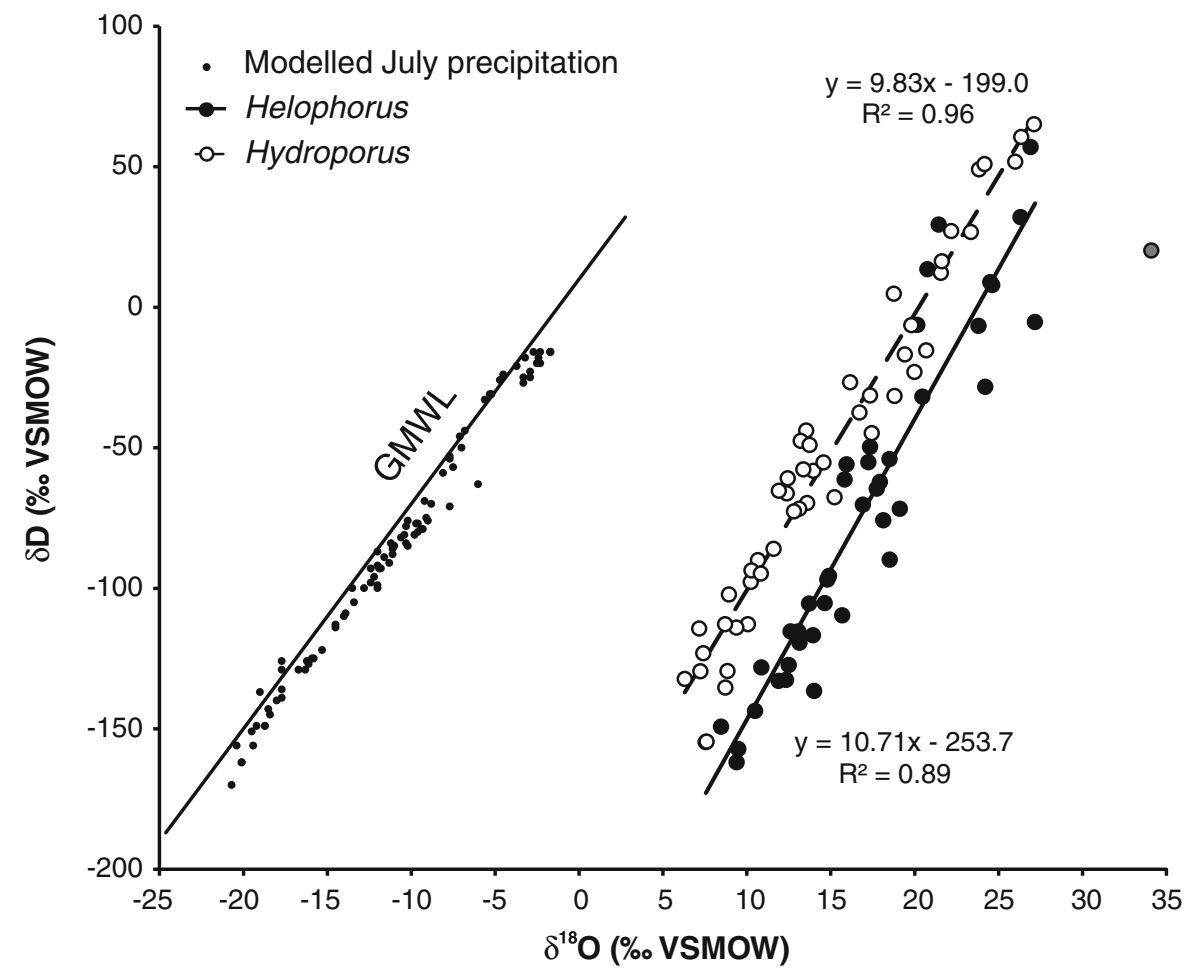

(http://ggweather.com/normals/), see Electronic Supplementary Material Table 1.

\section{Statistical analyses}

Ordinary least square regressions on the isotope data were done with PAST v2.14 (Hammer et al. 2001). Regression lines were considered similar if their $95 \%$ confidence intervals overlapped. Because the residuals of all regression lines were not normally distributed, the $95 \%$ confidence intervals were calculated using bootstrapping with 2,000 replicates (Hammer 2012). One specimen of Helophorus originating from a water tank in New Mexico was considered an outlier based on its high $\delta \mathrm{D}$ and $\delta^{18} \mathrm{O}$ values (Figs. 2, 3). Therefore, it was excluded from linear regressions.

\section{Results}

The isotopic values in both beetle genera ranged from 160 to $+65 \%$ for $\delta \mathrm{D}$ and from 7 to $34 \%$ for $\delta^{18} \mathrm{O}$ (Electronic Supplementary Material Table 1). A clear pattern could be observed in isotopic values of water beetles and modelled precipitation, with lowest values at high latitudes and highest values at low latitudes. Strong and highly significant $(p<0.001)$ relationships were observed between $\delta \mathrm{D}$ and $\delta^{18} \mathrm{O}$ in Hydroporus $\left(R^{2}=0.96\right.$; Fig. 1$)$ and Helophorus $\left(R^{2}=0.89\right)$. The slopes of the regression lines in Fig. 1 are similar for Helophorus and Hydroporus, which is indicated by overlapping $95 \%$ confidence intervals. Similarly, the $95 \%$ confidence intervals of the slopes of regression lines for the global meteoric water line (GMWL) and modelled precipitation in Fig. 1 overlap. There is, however, a difference in the slope of regression lines for environmental water and beetles, the latter being steeper than the GMWL.

Furthermore, strong relationships $(p<0.001)$ were found between isotope values in modelled July precipitation and isotope values in water beetles (Fig. 2). These were slightly stronger for Helophorus $\left(R^{2}=0.82\right.$ and 0.77 for $\delta^{18} \mathrm{O}$ and $\delta \mathrm{D}$, respectively) compared to Hydroporus $\left(R^{2}=0.72\right.$ and 0.71 for $\delta^{18} \mathrm{O}$ and $\delta \mathrm{D}$, respectively). The regression lines for Helophorus in Fig. 2 appear to have steeper slopes than those for Hydroporus, although there is overlap between the $95 \%$ confidence intervals of the regression slopes.

The difference $(\Delta)$ between isotope values in beetles and modelled July precipitation was calculated 
Fig. 2 Linear regression of isotopic composition of water beetles and modelled July precipitation for $\mathbf{a} \delta \mathrm{D}$ and $\mathbf{b} \delta^{18} \mathrm{O}$. Closed circles represent Helophorus, open circles represent

Hydroporus. One

Helophorus outlier is shown in grey
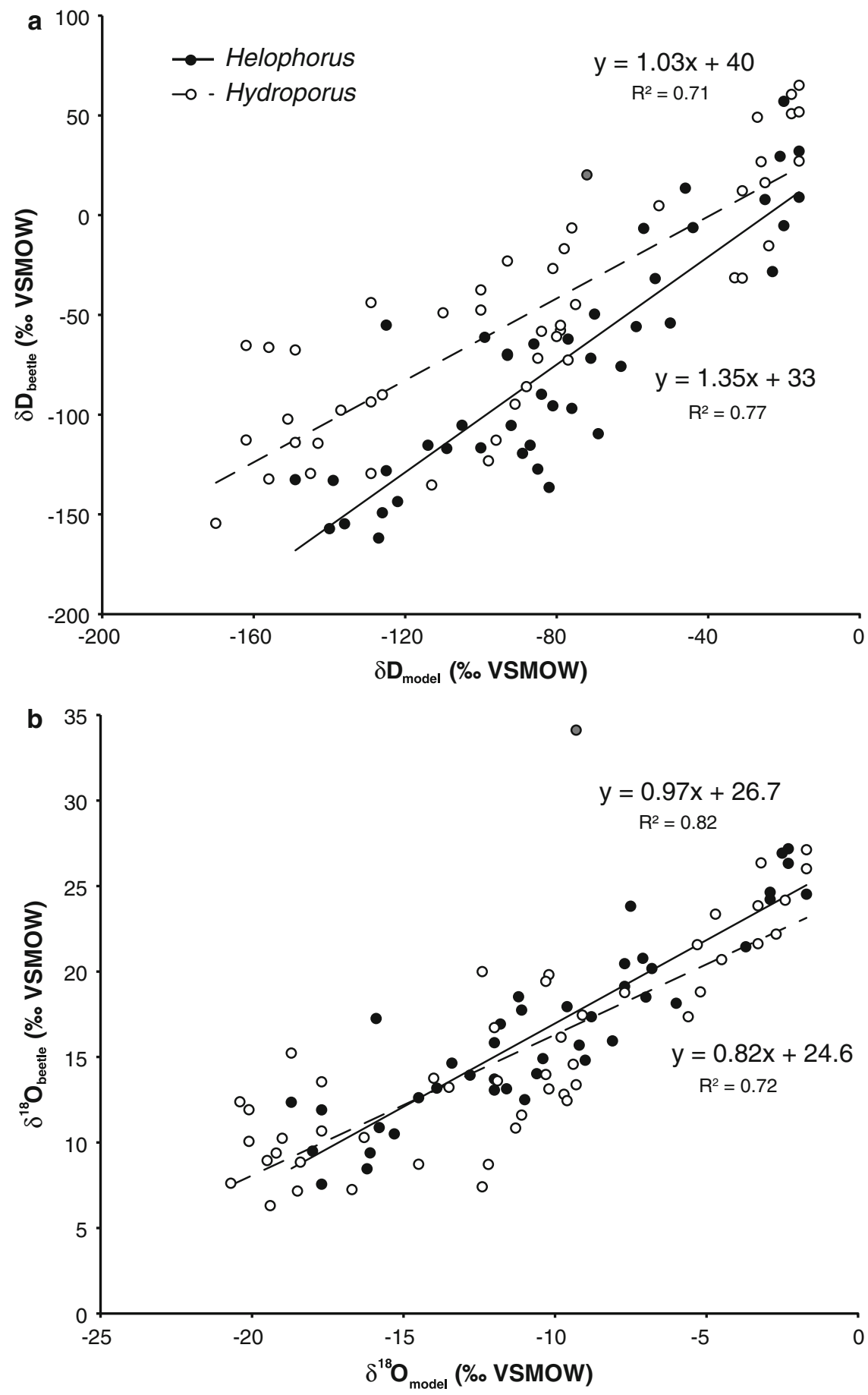

to test if geographical patterns could explain variations in $\Delta$ values. For this, a constant fractionation factor was assumed between environmental water and beetle tissue. Mean $\Delta \delta^{18} \mathrm{O}$ values (reported $\pm 1 \mathrm{SD}$ ) were very similar for Helophorus and Hydroporus
(27.0 $\pm 2.2 \%$ and $26.6 \pm 3.2 \%$, respectively). In contrast, mean $\Delta \delta \mathrm{D}$ values of Hydroporus (38 \pm $31 \%$ ) were $33 \%$ higher than mean $\Delta \delta \mathrm{D}$ values of Helophorus $(5 \pm 31 \%$ ). Considered as a group, $\Delta$ values were normally distributed, but geographical 
Fig. 3 Collection sites of a, b Helophorus and c,

d Hydroporus. For each site, $\Delta \delta^{18} \mathrm{O}$ (i.e. $\delta^{18} \mathrm{O}$ beetle $-\delta^{18} \mathrm{O}$ modelled July precipitation) and $\Delta \delta \mathrm{D}$ $(\delta \mathrm{D}$ beetle $-\delta \mathrm{D}$ modelled July precipitation) are plotted. Beetle samples with $\Delta$ values lower than the mean $\Delta$ values are indicated with circles, beetle samples with $\Delta$ values higher than mean $\Delta$ values are shown as plus signs. The magnitude of $\Delta$ values corresponds with the symbol size as indicated in the legend. Box-andwhiskers plots below each map indicate minimum, 25 th \%o, median, 75th \%o and maximum isotope values. One Helophorus outlier is indicated by times symbol
Helophorus
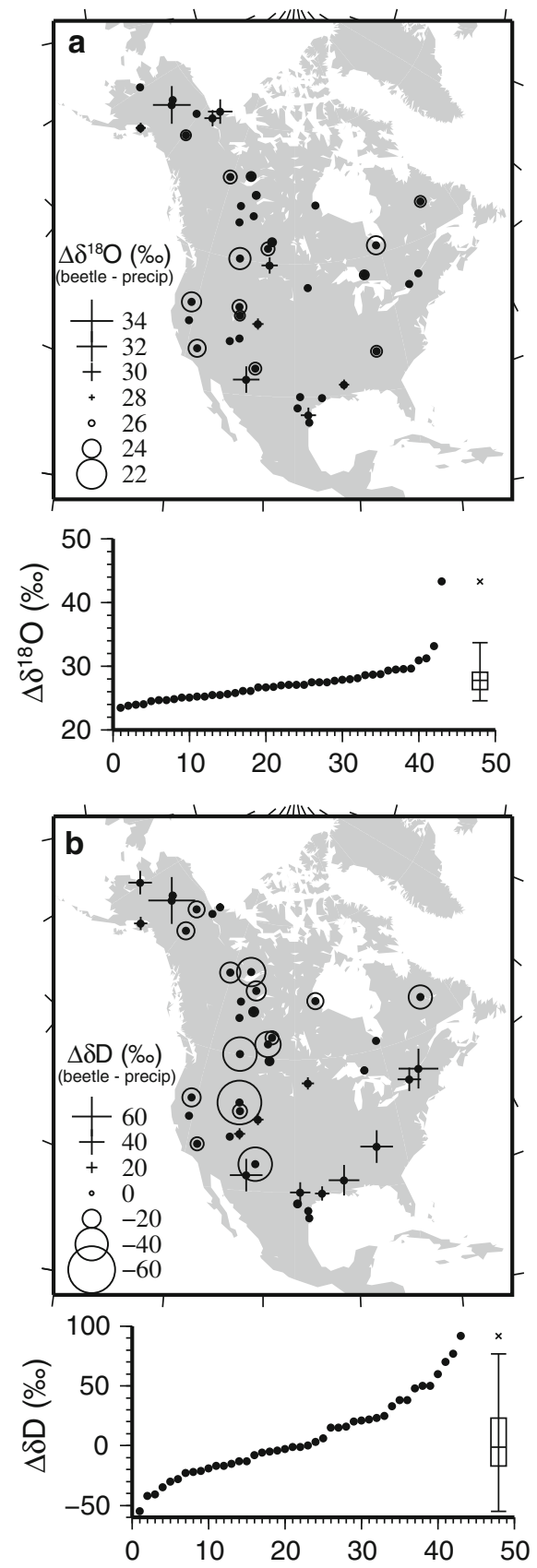

Hydroporus
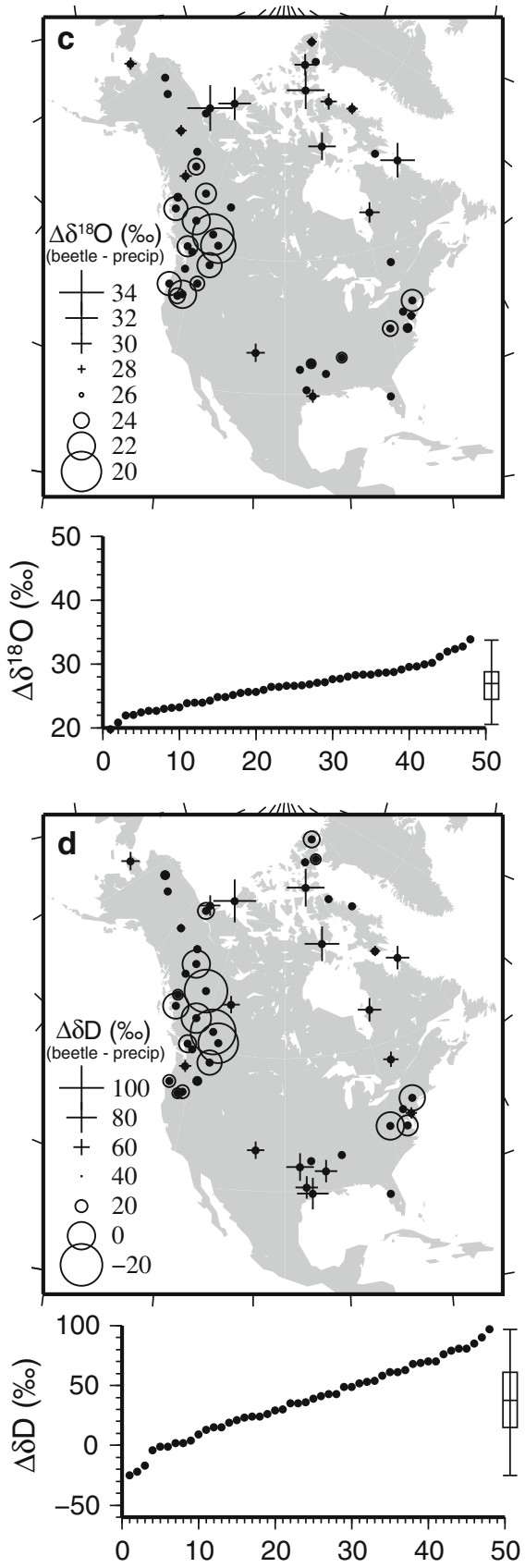

patterns indicate that $\Delta$ values reflect regional-scale climatic and hydrologic patterns. Sample locations with $\Delta$ values that were $>1$ SD lower than the mean $\Delta$ value are found predominantly in the Rocky Mountains and Coastal Mountains, whereas $\Delta$ values $>1$ SD higher than mean $\Delta$ values were found mostly in the Southern US and the Arctic (Fig. 3).

\section{Discussion}

$\delta \mathrm{D}$ and $\delta^{18} \mathrm{O}$ in water beetles and environmental water

The slope of the regression line for $\delta \mathrm{D}$ and $\delta^{18} \mathrm{O}$ values in beetle samples broadly reproduced the gradient in the 
GMWL (Fig. 1). The similarity between gradients in stable isotopes of water beetles and stable isotopes of modelled July precipitation on a continental scale indicates that the $\delta \mathrm{D}$ and $\delta^{18} \mathrm{O}$ values of environmental water from which water beetles derived their isotopic composition reflect $\delta \mathrm{D}$ and $\delta^{18} \mathrm{O}$ values of precipitation at the collection location. We used the isotope composition of July precipitation, because in this month both beetle genera have emerged and are active (Larson et al. 2000; Smetana 1985) and we observed higher correlation coefficients between stable isotope values in beetles and modelled precipitation in July compared with other months (data not shown).

We observed a difference in the slope of the regression lines for $\delta \mathrm{D}$ and $\delta^{18} \mathrm{O}$ when comparing environmental water and beetles (Fig. 1). This suggests that a stronger fractionation of hydrogen isotopes occurs in water beetles than in environmental water. Deuterium enrichment could happen by trophic discrimination (see "Offset between genera"), in metabolic processes, and during the synthesis of exoskeletons. For these processes, organic compounds derived from diet are important and the steeper regression slope for beetles in Fig. 1 may be an effect of deuterium-enriched diet. In order to investigate the importance of diet on water beetle $\delta \mathrm{D}$, experimental studies are required that analyse stable isotopes of water beetles that are raised using water and food with different isotope composition.

The average beetle $\delta^{18} \mathrm{O}$ values are offset from the modelled precipitation values by $27.0 \pm 2.2 \%$ and $26.6 \pm 3.2 \%$ on average for Helophorus and $\mathrm{Hy}$ droporus, respectively (Fig. 1). Offsets of a similar magnitude have been reported for other lacustrine invertebrates. Wooller et al. (2004) found an average offset of $28.5 \%$ between $\delta^{18} \mathrm{O}$ of local precipitation and chironomids and Verbruggen et al. (2011) found average offsets between $\delta^{18} \mathrm{O}$ of modelled precipitation and $\delta^{18} \mathrm{O}$ of chironomids and Cladocera of 25.6 and $23.3 \%$, respectively. The variation in offsets between different lacustrine invertebrates can be caused by differences in diet and metabolism (vital effects). For ostracods, it has been shown that $\delta^{18} \mathrm{O}$ of their calcite valves has taxon-specific variations (von Grafenstein et al. 1999b). To our knowledge, no systematic studies exist that assess taxon-specific effects on the $\delta^{18} \mathrm{O}$ and $\delta \mathrm{D}$ of chitinous remains of lacustrine invertebrates.

In addition to biochemical processes, $\delta^{18} \mathrm{O}$ and $\delta \mathrm{D}$ of beetle chitin are affected by several hydrological processes that affect the stable isotope composition of lake water at a site, which can deviate from the expected (modelled) isotope composition of environmental water. These processes include seasonal and annual variation in the isotope composition of precipitation (Dutton et al. 2005; Rozanski et al. 1993), moisture balance (Gibson et al. 2005, 2008), seasonal precipitation amounts (Shuman et al. 2006; Yu et al. 2002), snowpack volumes (Burnett et al. 2003), and atmospheric circulation patterns (Anderson et al. 2005; Smith and Hollander 1999). Because of these processes, stable isotopes of lake water and water beetles that live in it do not always reflect $\delta^{18} \mathrm{O}$ and $\delta \mathrm{D}$ of local precipitation. It can be expected, however, that the relationship between stable isotopes in water beetles and the lake water in which they live is much stronger than the relationship between isotopes in water beetles and (modelled) precipitation. Indeed, Verbruggen et al. (2011) found stronger correlations between $\delta^{18} \mathrm{O}$ of invertebrates and $\delta^{18} \mathrm{O}$ of lake water than between invertebrate $\delta^{18} \mathrm{O}$ and $\delta^{18} \mathrm{O}$ of modelled precipitation in a study of 31 lakes along a latitudinal gradient in Europe.

For the sites in our study, we calculated the difference between isotope values in beetles and modelled precipitation $(\Delta)$. The $\Delta$ values had a standard deviation of $31.4 \%$ o $(\delta \mathrm{D})$ and $2.2 \%$ ( $\left(\delta^{18} \mathrm{O}\right)$ for Helophorus and $31.0 \%$ o $(\delta \mathrm{D})$ and $3.2 \% 0\left(\delta^{18} \mathrm{O}\right)$ for Hydroporus from the mean $\Delta$ values (Fig. 3), which is small compared to the observed range of isotope values in this study. This suggests that the isotopic composition of water beetles from the majority of sites in this study was similar to the expected isotopic values of modelled July precipitation. This extensive dataset confirms earlier studies (Gröcke et al. 2006; Hobson et al. 1999b; Miller et al. 1988; Nielson and Bowen 2010; Schimmelmann et al. 1993; Verbruggen et al. 2011; Wooller et al. 2004) that investigated the relationship between $\delta \mathrm{D}$ or $\delta^{18} \mathrm{O}$ in various freshwater and terrestrial invertebrates and isotopic values of (modelled) environmental water. For certain types of sites, however, the $\Delta$ values were $>1$ SD from the mean $\Delta$ value (Fig. 3). These sites were distributed unevenly, with some geographic regions showing anomalous concentrations of positive or negative $\Delta$ values. Relatively ${ }^{18} \mathrm{O}$ - and D-enriched values in beetles were observed at sites that included small and closed basins located in especially warm, arid areas in the Southern US and polar deserts in the Arctic (Fig. 3). Such sites 
are expected to be highly evaporative and ${ }^{18} \mathrm{O}$ - and D-enriched (Gat 1995; Gibson 2002; Gibson and Edwards 2002). In contrast, relatively ${ }^{18} \mathrm{O}$ - and D-depleted values in beetles were mostly observed at locations that were fed by snow melt from the Rocky Mountains and Coastal Mountains (Fig. 3), which is depleted in ${ }^{18} \mathrm{O}$ and D (Gat 1995; Henderson and Shuman 2009). Where winter precipitation is a major component of the water budget, the $\delta \mathrm{D}$ and $\delta^{18} \mathrm{O}$ values of surface waters, even in summer, remain lower than those of summer precipitation. Overall, the $\Delta$ values were not related to temperature at the collection locations, suggesting that hydrogen and oxygen isotopes of water beetles in this data set are not affected by a temperature-dependent fractionation during the formation of the elytra.

\section{Offset between genera}

Environmental water is the source of approximately $69 \%$ of oxygen isotopes in aquatic invertebrates (Nielson and Bowen 2010; Wang et al. 2009) and 6 to $39 \%$ of hydrogen isotopes (Solomon et al. 2009; Wang et al. 2009). Diet is another source that determines the isotopic composition of chitin (Schimmelmann and DeNiro 1986) and, furthermore, fractionation of hydrogen isotopes can occur as organic matter passes through the food chain (Birchall et al. 2005; Hedges et al. 2006; Hobson et al. 1999a). This could explain why the offsets between $\delta \mathrm{D}$ values of beetles and modelled precipitation are $33 \%$ larger for Hydroporus than for Helophorus (Fig. 1), because predaceous Hydroporus has a higher trophic position than scavenging Helophorus. These results correspond with results of Schimmelmann and DeNiro (1986) who observed that chitin of totally predaceous arthropods shows $31 \%$ more positive $\delta \mathrm{D}$ values compared to the chitin of predominantly herbivorous species, including filter feeders; the $\delta \mathrm{D}$ values of chitin from omnivorous arthropods fall in the middle. An effect of trophic position on $\delta \mathrm{D}$ has also been observed in analysis of bone collagen of fish and mammals and keratin of bird feathers (Birchall et al. 2005; Reynard and Hedges 2008; Soto et al. 2011), but experimental studies with monarch butterflies (Hobson et al. 1999b) and aquatic consumers (Solomon et al. 2009), showed negligible trophic enrichment. We found no evidence for trophic discrimination of oxygen isotopes, as the offset between $\delta^{18} \mathrm{O}$ values of beetles and $\delta^{18} \mathrm{O}$ of modelled precipitation was the same for both genera (Fig. 1). This is in support of findings by Schimmelmann and DeNiro (1986), who did not observe a significant correlation between $\delta^{18} \mathrm{O}$ values in arthropod chitin and trophic level.

Implications for palaeoclimate studies

The strong correlations between isotopic composition of water beetles and modelled local precipitation can also contain a climate signal, based on the widelyobserved correlation between isotopic composition of local precipitation and temperature (Dansgaard 1964; Rozanski et al. 1993). The uncertainty about the isotopic composition of environmental water of the sites where beetles were originally collected, however, limits the potential to infer temperatures from this data set. Palaeoclimatological applications will be less affected by this issue if a single location is chosen, which is not prone to extreme evaporation or influx of snow melt and which has a relatively long residence time of the environmental water, thereby reducing the seasonal variability in isotopic composition of environmental water (Gasse 2005; Gat 1995). The results in this study suggest that the isotopic composition of water beetle remains from an undisturbed sediment record from a suitable location could provide information about changes in isotopic composition of local precipitation.

\section{Conclusions}

The strong correlation between $\delta \mathrm{D}$ and $\delta^{18} \mathrm{O}$ values in water beetles and the systematic offset from the GMWL suggest that the chitinous exoskeletons of water beetles contain information about the isotopic composition of the environmental water in which they lived. This is supported by the strong correlation between the isotopic composition of water beetles and modelled July precipitation, indicating the potential to trace the geographical origin of water beetles based on their isotopic composition.

Furthermore, our data suggest that fractionation of isotopes during transfer to higher trophic levels occurs with stable hydrogen isotopes, whereas this was not observed for stable oxygen isotopes. Ideally, only remains of beetles from the same species or genus are used, to minimize noise in the data caused by inter- 
species differences (e.g. diet, habitat, life cycle). This is especially important when comparing $\delta \mathrm{D}$ values of beetles from different sampling locations or stratigraphic horizons. For downcore analysis of beetle $\delta^{18} \mathrm{O}$, it is less critical to reduce variation in water beetle taxa, as long as terrestrial beetles are excluded. In a single, hydrologically stable location, it should therefore be possible to reconstruct changes in past isotopic composition of environmental water and local precipitation using the isotopic composition of water beetle remains.

Acknowledgments The museum specimens were kindly provided (i.e. sacrificed) by Dr. P. Bouchard and Mr. A. E. Davies at the Canadian National Collection of Insects, Agriculture and Agri-Food Canada. We thank Jonathan Holmes and three anonymous reviewers for their constructive remarks on earlier versions of this manuscript. Support for van Hardenbroek's dissertation research was provided by a NERC training grant NE/ E522959/1. This project was supported by a grant from the Natural Sciences and Engineering Research Council of Canada Discovery Grant to DRG (No. 288321).

\section{References}

Anderson L, Abbott MB, Finney BP, Burns SJ (2005) Regional atmospheric circulation change in the North Pacific during the Holocene inferred from lacustrine carbonate oxygen isotopes, Yukon Territory, Canada. Quat Res 64:21-35

Barker PA, Street-Perrott FA, Leng MJ, Greenwood PB, Swain DL, Perrott RA, Telford RJ, Ficken KJ (2001) A 14,000year oxygen isotope record from diatom silica in two Alpine Lakes on Mt. Kenya. Science 292:2307-2310

Birchall J, O'Connell TC, Heaton THE, Hedges REM (2005) Hydrogen isotope ratios in animal body protein reflect trophic level. J Anim Ecol 74:877-881

Bowen GJ, Revenaugh J (2003) Interpolating the isotopic composition of modern meteoric precipitation. Water Resour Res 39:1299

Bowen GJ, Wilkinson B (2002) Spatial distribution of $\delta^{18} \mathrm{O}$ in meteoric precipitation. Geology 30:315-318

Bowen GJ, Wassenaar LI, Hobson KA (2005) Global application of stable hydrogen and oxygen isotopes to wildlife forensics. Oecologia 143:337-348

Burnett AW, Kirby ME, Mullins HT, Patterson WP (2003) Increasing Great Lake: effect snowfall during the twentieth century - a regional response to global warming? J Clim $16: 3535-3542$

Dansgaard W (1964) Stable isotopes in precipitation. Tellus $16: 436-468$

Dutton A, Wilkinson BH, Welker JM, Bowen GJ, Lohmann KC (2005) Spatial distribution and seasonal variation in $\delta 180$ of modern precipitation and river water across the conterminous USA. Hydrol Process 19:4121-4146
Eicher U, Siegenthaler U (1976) Palynological and oxygen isotope investigatins on Late-Glacial sediment cores from Swiss lakes. Boreas 5:109-117

Elias SA (2006) Quaternary beetle research: the state of the art. Quat Sci Rev 25:1731-1737

Gasse F (2005) Isotopic palaeolimnology. In: Aggarwal K, Gat JR, Frohlich KFO (eds) Isotopes in the water cycle. Springer, Dordrecht, pp 353-358

Gat JR (1995) Stable isotopes of fresh and saline lakes. In: Lerman A, Imboden DM, Gat JR (eds) Physics and chemistry of lakes. Springer, Berlin, pp 139-195

Gibson JJ (2002) Short-term evaporation and water budget comparisons in shallow Arctic lakes using non-steady isotope mass balance. J Hydrol 264:242-261

Gibson JJ, Edwards TWD (2002) Regional water balance trends and evaporation-transpiration partitioning from a stable isotope survey of lakes in northern Canada. Glob Biogeochem Cycles 16:1026. doi:10.1029/2001GB001839

Gibson JJ, Edwards TWD, Birks SJ, Amour NA, Buhay WM, McEachern P, Wolfe BB, Peters DL (2005) Progress in isotope tracer hydrology in Canada. Hydrol Process 19: 303-327

Gibson JJ, Birks SJ, Edwards TWD (2008) Global prediction of $\delta \mathrm{A}$ and $\delta^{2} \mathrm{H}-\delta^{18} \mathrm{O}$ evaporation slopes for lakes and soil water accounting for seasonality. Glob Biogeochem Cycles 22:GB2031. doi:10.1029/2007GB002997

Gröcke DR, Schimmelmann A, Elias S, Miller RF (2006) Stable hydrogen-isotope ratios in beetle chitin: preliminary European data and re-interpretation of North American data. Quat Sci Rev 25:1850-1864

Hammer Ø (2012) Past, paleontological statistics version 2.14, reference manual. Natural History Museum, University of Oslo, Oslo

Hammer $\varnothing$, Harper DAT, Ryan PD (2001) PAST: paleontological statistics software package for education and data analysis. Palaeontol Electr 4:9

Hedges REM, Stevens RE, Koch PL (2006) Isotopes in bone and teeth. In: Leng MJ (ed) Isotopes in palaeoenvironmental research. Springer, Dordrecht, pp 117-145

Henderson AK, Shuman BN (2009) Hydrogen and oxygen isotopic compositions of lake water in the western United States. Geol Soc Am Bull 121:1179-1189

Hobson KA, Atwell L, Wassenaar LI (1999a) Influence of drinking water and diet on the stable-hydrogen isotope ratios of animal tissues. Proc Natl Acad Sci USA 96: 8003-8006

Hobson KA, Wassenaar LI, Taylor OR (1999b) Stable isotopes $\left(\delta \mathrm{D}\right.$ and $\delta^{13} \mathrm{C}$ ) are geographic indicators of natal origins of monarch butterflies in eastern North America. Oecologia 120:397-404

IAEA/WMO (2006) Global network of isotopes in precipitation. The GNIP database. Accessible at: http://www.iaea. org/water

Larson DJ, Alaire Y, Roughley RE (2000) Predaceous diving beetles (Coleoptera: Dytiscidae) of the Nearctic Region, with emphasis on the fauna of Canada and Alaska. NRC Research Press, Ottawa

Leng MJ, Barker PA (2006) A review of the oxygen isotope composition of lacustrine diatom silica for palaeoclimate reconstruction. Earth-Sci Rev 75:5-27 
Miller RF, Fritz P, Morgan AV (1988) Climatic implications of $\mathrm{D} / \mathrm{H}$ ratios in beetle chitin. Palaeogeogr Palaeoclimatol Palaeoecol 66:277-288

Nielson KE, Bowen GJ (2010) Hydrogen and oxygen in brine shrimp chitin reflect environmental water and dietary isotopic composition. Geochim Cosmochim Acta 74:1812-1822

Reynard LM, Hedges REM (2008) Stable hydrogen isotopes of bone collagen in palaeodietary and palaeoenvironmental reconstruction. J Archaeol Sci 35:1934-1942

Rozanski K, Araguás-Araguás L, Gonfiantini R (1993) Isotopic patterns in modern global precipitation. Geophys Monogr 78:1-36

Sauer PE, Miller GH, Overpeck JT (2001) Oxygen isotope ratios of organic matter in arctic lakes as a paleoclimate proxy: field and laboratory investigations. J Paleolimnol 25:43-64

Schimmelmann A, DeNiro MJ (1986) Stable isotopic studies on chitin. III. The $\mathrm{D} / \mathrm{H}$ and ${ }^{18} \mathrm{O} /{ }^{16} \mathrm{O}$ ratios in arthopod chitin. Geochim Cosmochim Acta 50:1485-1496

Schimmelmann A, Miller RF (2002) Review of methods for the determination of deuterium/hydrogen stable isotope ratios in chitin. In: Muzzarelli RAA, Muzzarelli C (eds) Chitosan in pharmacy and chemistry. Atec Edizioni, Grottammare, pp 469-474

Schimmelmann A, Miller RF, Leavitt SW (1993) Hydrogen isotopic exchange and stable isotope ratios in cellulose, wood, chitin, and amino compounds. Geophys Monogr 78:367-374

Shuman B, Huang Y, Newby P, Wang Y (2006) Compoundspecific isotopic analyses track changes in seasonal precipitation regimes in the Northeastern United States at ca 8,200 cal yr BP. Quat Sci Rev 25:2992-3002

Smetana A (1985) Revision of the subfamily Helophorinae of the Nearctic region (Coleoptera: Hydrophilidae). Mem Entomol Soc Can 131:1-154

Smith MA, Hollander DJ (1999) Historical linkage between atmospheric circulation patterns and the oxygen isotopic record of sedimentary carbonates from Lake Mendota, Wisconsin, USA. Geology 27:589-592

Solomon C, Cole J, Doucett R, Pace M, Preston N, Smith L, Weidel B (2009) The influence of environmental water on the hydrogen stable isotope ratio in aquatic consumers. Oecologia 161:313-324

Soto DX, Wassenaar LI, Hobson KA, Catalan J (2011) Effects of size and diet on stable hydrogen isotope values $(\delta \mathrm{D})$ in fish: implications for tracing origins of individuals and their food sources. Can J Fish Aquat Sci 68:2011-2019

Verbruggen F, Heiri O, Reichart GJ, Blaga C, Lotter AF (2011) Stable oxygen isotopes in chironomid and cladoceran remains as indicators for lake-water $\delta^{18} \mathrm{O}$. Limnol Oceanogr 56:2071-2079

von Grafenstein U, Erlenkeuser H, Brauer A, Jouzel J, Johnsen SJ (1999a) A Mid-European decadal isotope-climate record from 15,500 to 5,000 years BP. Science 284 : 1654-1657

von Grafenstein U, Erlernkeuser H, Trimborn P (1999b) Oxygen and carbon isotopes in modern fresh-water ostracod valves: assessing vital offsets and autecological effects of interest for palaeoclimate studies. Palaeogeogr Palaeoclimatol Palaeoecol 148:133-152

Wang Y, O'Brien D, Jenson J, Francis D, Wooller M (2009) The influence of diet and water on the stable oxygen and hydrogen isotope composition of Chironomidae (Diptera) with paleoecological implications. Oecologia 160:225-233

Wassenaar LI, Hobson KA (2003) Comparative equilibration and online technique for determination of non-exchangeable hydrogen of keratins for use in animal migration studies. Isot Environ Health Stud 39:211-217

Wolfe BB, Falcone MD, Clogg-Wright KP, Mongeon CL, Yi Y, Brock BE, Amour NA, Mark WA, Edwards TWD (2007) Progress in isotope paleohydrology using lake sediment cellulose. J Paleolimnol 37:221-231

Wooller MJ, Francis D, Fogel ML, Miller GH, Walker IR, Wolfe AP (2004) Quantitative paleotemperature estimates from $\delta^{18} \mathrm{O}$ of chironomid head capsules preserved in arctic lake sediments. J Paleolimnol 31:267-274

Yu Z, Ito E, Engstrom DR (2002) Water isotopic and hydrochemical evolution of a lake chain in the northern Great Plains and its paleoclimatic implications. J Paleolimnol 28:207-217 